Lepr Rev (2000) 71, 169-178

\title{
The age-dependent deterioration in light touch sensation on the plantar aspect of the foot in a rural community in India: implications when screening for sensory impairment
}

\author{
P. D. MITCHELL \& T. N. MITCHELL \\ Philadelphia Leprosy Hospital, Salur, Vizianagaram District, Andhra \\ Pradesh 532 591, India
}

Accepted for publication 18 February 2000

\begin{abstract}
Summary Regular testing for impaired sensation is important in the management of diseases that can cause progressive nerve damage, such as leprosy. It has been shown that light touch sensibility decreases with age in the hands of healthy individuals, but little research has been undertaken to assess possible changes in the feet in developing countries. This information is needed to allow an appropriate level of sensation to be chosen when screening for nerve damage in the foot. To clarify this, a cross-sectional study on male adults was carried out in the rural town of Salur, Andhra Pradesh, India. A range of Semmes-Weinstein monofilaments were employed at 12 locations on the foot to determine sensation to light touch stimuli in individuals from each decade of adult life. It was found that in this population, sensibility threshold in the foot increases with age and this was noted in both soft and callous skin. This shows the increase was due to neurological factors, not merely due to an increase in callous deposition with advancing age. In the majority of individuals in their fifties and sixties, the callous skin at the forefoot and heel was unable to detect the 5.07 monofilament (equivalent to $8-12 \mathrm{~g}$ ), previously recommended as a method to screen for plantar neuropathy. All areas of all feet were able to detect the 5.46 filament (approximately $30 \mathrm{~g}$ ). The size of this study (54 individuals) prevents the determination of definitive normal ranges for each decade of life in this population. However, it does demonstrate the degree to which sensation deteriorates with age and could be used as an approximate guide when interpreting the results of sensory testing in similar rural areas of the developing world.
\end{abstract}

\section{Introduction}

The feet of leprosy patients are prone to sensory impairment following lesions of peripheral nerves. Often neuropathy persists after microbiological cure and the challenge of prevention of complications can remain throughout life. Complications in the foot include resorption of

Correspondence to: Dr Piers Mitchell, 2 Milton Mansions, Queens Club Gardens, London W14 9RP, UK (e-mail: p.mitchell@clara.co.uk) 
the toes, paralysis of the intrinsic muscles of the foot, cracks and fissures in excessively keratinized skin, ulceration on the plantar surface of the foot, osteomyelitis and malignancy. ${ }^{1}$ In consequence, screening programmes have been established in leprosy control programmes so that nerve damage is identified as early as possible. Sensory testing is used both in the diagnosis of leprosy and also for monitoring patients to prevent new nerve damage from occurring. Any screening tool must be able to distinguish those with normal sensation from those with impaired nerve function at all ages. Without knowing what is normal, the recommendation of a screening tool to identify the abnormal is difficult.

The effect of ageing on light touch sensibility in the developing world requires clarification. Studies in developed countries have found that touch sensibility in the big toe deteriorates with advancing age, ${ }^{2}$ and similar changes have been noted in the hands. ${ }^{3,4}$ Two studies have briefly mentioned variation in sensibility with age in developing countries and have confirmed sensory deterioration with advancing age; sensation thresholds also appear to be higher than in more developed countries. ${ }^{5,6}$ However, it is not clear if sensation of the soft skin of the toes and arch deteriorates in the same way as callous skin, so it is not known if the change is secondary to the build up of callous with age or deterioration in neurological function. Nor has the deterioration in sensation with age been discussed with regards to choosing a filament for screening purposes.

Graded monofilaments have been shown to be a sensitive, reproducible and practical method for both diagnostic screening for nerve damage and monitoring of sensation in the foot. $^{7-9}$ Our aim was to use these monofilaments to assess any change in light touch sensibility in the foot with increasing age. For this study, monofilaments of filament index $4.56,5.07$ and 5.46 were used. They are classically described as applying a force to the skin equivalent to roughly 4,10 and 30 g. ${ }^{10,11}$

\section{Materials and methods}

Fifty-four healthy male individuals from the rural town of Salur in Andhra Pradesh State, India were asked to take part in the study and all agreed. They were not selected in a completely random manner, but were matched for age, occupation and footwear type with the cohort of male leprosy patients released from treatment from the town leprosy hospital between 1983 and 1988. This was to facilitate later research on these patients by using the findings of this study as a control. All of the individuals under study were without evidence of neurological disease. Since few participants knew their age more accurately than to the nearest decade, they were grouped in 10-year age bands. Only men were assessed, to minimize any variation in daily activity, and so foot stresses, associated with the differing roles of men and women in this population. No participant had sufficiently heavy alcohol intake to cause neuropathy. In an area characterized by monsoon and dry seasons, it might be expected that plantar sensation would vary as the skin becomes softened in the wet months and slowly hardens afterwards. In consequence, a study on the same individuals might yield differing results depending on the season. Again, high temperatures and humidity are thought to alter the properties of the Semmes-Weinstein nylon monofilaments, so that they buckle more easily than in cooler, dryer climates, and exert less force. ${ }^{10}$ This work was undertaken during the months of November and December, at the end of the monsoon, with high humidity and temperatures typically between 20 and $30^{\circ} \mathrm{C}$.

The Semmes-Weinstein monofilaments were tested on a Sartorius L2200P top-loading 
balance to confirm their accuracy. Each filament was tested five times by applying perpendicularly to the balance until bowing, using a technique described elsewhere and the mean force calculated. The diameters were also checked using a binocular light microscope linked by a video camera to an RGB software package and compared with past work. The filament index numbers $\left(\log _{10} \times\right.$ force required to bow the filament in tenths of $\left.\mathrm{mg}\right)$ were then confirmed by consulting past research. ${ }^{10,11}$ The mean force exerted by the filament of index 4.56 was $3.1 \mathrm{~g}$, by index $5.07,8.0 \mathrm{~g}$ and by index $5.46,29.5 \mathrm{~g}$. It is well known that monofilaments do not exert exactly the same force in practice as recorded by any of the manufacturers, as they are not made to exacting standards, ${ }^{13}$ to make them more affordable. Variation tends to become more obvious as the index numbers become larger, and so the filaments thicker. The values listed here are comparable with past studies of the forces exerted by these nylon monofilaments. ${ }^{10,11}$ Here we refer to the monofilament by its index number rather than by an estimation of the force it exerts.

All the patients and controls were examined by the same clinician to avoid inter-observer variation. Sensory function was assessed at the five toes, immediately distal to the first, third and fifth metatarsal heads, in the midfoot laterally and at the arch medially, and lateral and medial points on the heel, making 12 locations in all. The tests, outlined in detail elsewhere, ${ }^{10,11,14}$ took place in quiet surroundings and were explained to each participant who then looked away from his feet. Semmes-Weinstein monofilaments with index 4.56, 5.07 and 5.46 were applied to each of the 12 locations in a concealed and random manner. The lightest filament detected at each location was documented.

\section{Results}

A summary of the characteristics of the group with regard to age, class of occupation and footwear is shown in Table 1. The group was tested with the range of monofilaments to determine the normal sensation in this population. Light touch sensation was not statistically significantly different between the left and right feet, so data from just the right foot of each individual were used in the analysis. This data are summarized in Table 2.

Table 1. Summary of the study population with regard to age (a), occupation (b) and footwear (c) $(n=54)$

\begin{tabular}{|c|c|c|c|c|}
\hline \multicolumn{5}{|l|}{ Age groups } \\
\hline Age in years & $30-39$ & $40-49$ & $50-59$ & $60-69$ \\
\hline No. in age range $(\%)$ & $12(22)$ & $16(30)$ & $18(33)$ & $8(15)$ \\
\hline \multicolumn{5}{|l|}{ b } \\
\hline \multicolumn{5}{|l|}{ Occupation } \\
\hline Light work (e.g. in of fice/shop) & $22 \%$ & & & \\
\hline Heavy work (e.g. labourer/farmer) & $78 \%$ & & & \\
\hline \multicolumn{5}{|l|}{ c } \\
\hline \multicolumn{5}{|l|}{ Use of footwear } \\
\hline Use of footwear & None & Sandals & Shoes & \\
\hline At work & $15 \%$ & $85 \%$ & $0 \%$ & \\
\hline At home & $100 \%$ & $0 \%$ & $0 \%$ & \\
\hline
\end{tabular}


Table 2. Sensibility thresholds in each age group

\begin{tabular}{|c|c|c|c|c|}
\hline \multirow[t]{2}{*}{ Filament size } & \multicolumn{4}{|c|}{ No. of individuals detecting each filament } \\
\hline & $\begin{array}{c}30-39 \\
(n=12)\end{array}$ & $\begin{array}{c}40-49 \\
(n=16)\end{array}$ & $\begin{array}{c}50-59 \\
(n=18)\end{array}$ & $\begin{array}{c}60-69 \\
(n=8)\end{array}$ \\
\hline \multicolumn{5}{|l|}{ Location 1} \\
\hline 4.56 & 7 & 5 & 2 & 0 \\
\hline 5.07 & 2 & 7 & 9 & 3 \\
\hline 5.46 & 3 & 4 & 7 & 5 \\
\hline \multicolumn{5}{|l|}{ Location 2} \\
\hline 4.56 & 9 & 11 & 9 & 0 \\
\hline 5.07 & 2 & 5 & 7 & 6 \\
\hline 5.46 & 1 & 0 & 2 & 2 \\
\hline \multicolumn{5}{|l|}{ Location 3} \\
\hline 4.56 & 9 & 11 & 9 & 0 \\
\hline 5.07 & 2 & 5 & 7 & 6 \\
\hline 5.46 & 1 & 0 & 2 & 2 \\
\hline \multicolumn{5}{|l|}{ Location 4} \\
\hline 4.56 & 9 & 11 & 9 & 0 \\
\hline 5.07 & 2 & 5 & 6 & 6 \\
\hline 5.46 & 1 & 0 & 3 & 2 \\
\hline \multicolumn{5}{|l|}{ Location 5} \\
\hline 4.56 & 9 & 11 & 9 & 0 \\
\hline 5.07 & 2 & 5 & 4 & 6 \\
\hline 5.46 & 1 & 0 & 5 & 2 \\
\hline \multicolumn{5}{|l|}{ Location 6} \\
\hline 4.56 & 3 & 4 & 2 & 0 \\
\hline 5.07 & 4 & 6 & 6 & 1 \\
\hline 5.46 & 5 & 6 & 10 & 7 \\
\hline \multicolumn{5}{|l|}{ Location 7} \\
\hline 4.56 & 5 & 4 & 2 & 0 \\
\hline 5.07 & 3 & 8 & 4 & 1 \\
\hline 5.46 & 4 & 4 & 12 & 7 \\
\hline \multicolumn{5}{|l|}{ Location 8} \\
\hline 4.56 & 5 & 4 & 2 & 0 \\
\hline 5.07 & 3 & 7 & 4 & 1 \\
\hline 5.46 & 4 & 5 & 12 & 7 \\
\hline \multicolumn{5}{|l|}{ Location 9} \\
\hline 4.56 & 10 & 12 & 10 & 1 \\
\hline 5.07 & 2 & 4 & 3 & 5 \\
\hline 5.46 & 0 & 0 & 3 & 2 \\
\hline \multicolumn{5}{|l|}{ Location 10} \\
\hline 4.56 & 4 & 3 & 0 & 0 \\
\hline 5.07 & 3 & 4 & 5 & 0 \\
\hline 5.46 & 5 & 9 & 13 & 8 \\
\hline \multicolumn{5}{|l|}{ Location 11} \\
\hline 4.56 & 1 & 0 & 0 & 0 \\
\hline 5.07 & 4 & 5 & 1 & 0 \\
\hline 5.46 & 7 & 11 & 17 & 8 \\
\hline \multicolumn{5}{|l|}{ Location 12} \\
\hline 4.56 & 0 & 0 & 0 & 0 \\
\hline 5.07 & 4 & 5 & 1 & 0 \\
\hline 5.46 & 8 & 11 & 17 & 8 \\
\hline
\end{tabular}

Numbers in italics represent locations.

Callous skin is present at locations $1,6,7,8,10,11$ and 12 .

Soft skin is present at locations $2,3,4,5$ and 9. 


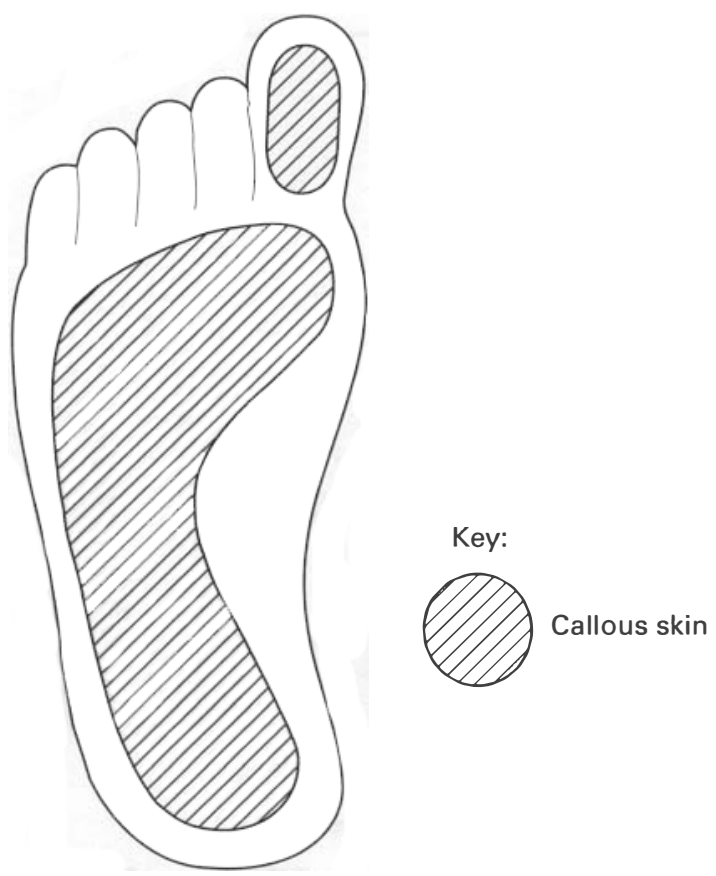

Figure 1. Distribution of callous skin on the plantar aspect of the foot.

To investigate the relationship between age and sensation threshold across all locations, a score out of 5 was given for soft skin (as there are five locations in areas of soft skin) and similarly out of seven for callous skin (Figure 1). For example, if subject A could feel the 4.56 filament as the lightest filament at locations 2, 3, 4 and 5, and the 5.07 filament at location 9, this would score 4 for the 4.56 filament, 1 for the 5.07 filament and 0 for the 5.46 filament. The use of this technique avoids inappropriately inflating the power of the tests by appearing to increase the number of individuals in the study by a factor of 12 (the number of locations). The Spearman's rho correlation coefficient was calculated for each filament across age groups. Detection of the 4.56 filament in both soft and callous skin was noted to decrease significantly with increasing age $(P=0.001)$. Detection of the 5.07 filament in soft skin also decreased significantly with age $(P=0.019)$ but there was no significant difference in callous skin. Conversely, there was a significant increase with age where only the 5.46 filament was detected, occurring in both soft $(P=0.025)$ and callous skin $(P=0.001)$. This relationship between age and sensibility threshold over all locations is shown in Figure 2. Examples of the relationship at the representative locations 1 (callous skin) and 9 (soft skin) is shown in Figure 3. Pearson chi-square test at individual locations also showed that there was a significant increase in sensory threshold with increasing age on comparing those in their thirties with those in their sixties (for example, $P=0.037$ for location 1 and $P=0.028$ for location 9).

A comparison between sensation at locations in soft skin areas and that in callous skin areas showed a significant difference between the groups. Analysis was performed using the Wilcoxon Signed Ranks test to compare the difference between soft and callous skin in each individual for the entire group. This demonstrated that soft skin had a lower sensation threshold than callous skin $(P<0.001)$. 


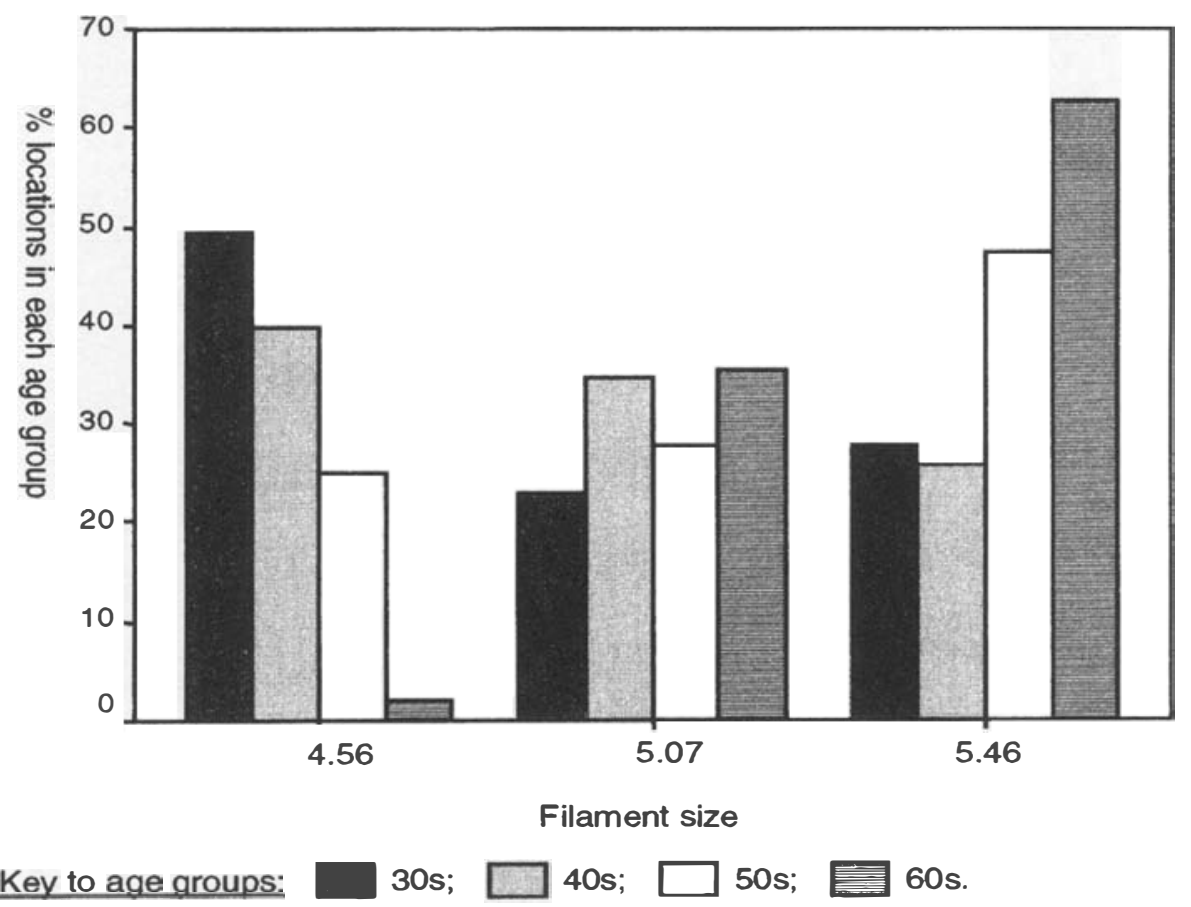

Figure 2. Graph showing the relationship between age and sensibility threshold to light touch at all locations.

A comparison between sensation in callous skin on the forefoot was compared with the heel, again using the Wilcoxon Signed Ranks test. The heel had a significantly higher sensory threshold in all age groups than the big toe $(P<0.001$ in all age groups). These differences can be seen graphically in Figure 3, where sensibility threshold is shown for the callous skin at locations 1 and 12 and soft skin at location 9.

The final area of interest is the identification of the filament that can be detected by all individuals in all age groups at all locations on the foot. There were 648 locations in all on the right feet of the 54 individuals. Looking at all age groups combined, $31 \%$ of these locations detected the 4.56 filament, $30 \%$ were unable to detect this but could detect the 5.07 filament, while $39 \%$ detected only the 5.46 filament. Of particular note was that $81 \%$ of locations on the heel were only able to detect the 5.46 filament, nothing lighter. All locations in all feet were able to detect the 5.46 filament.

To summarize these results, firstly there is a clear and gradual deterioration in sensory acuity with age. Secondly, regardless of age, those areas covered with callus skin had a higher sensibility threshold than those covered with soft skin. Thirdly, the callous skin at the heel had a higher sensibility threshold than the callous skin of the forefoot. Finally, the callous skin at many locations was unable to detect any filament lighter than 5.46, most notably at the heel.

\section{Discussion}

In order to identify the abnormal, which is the purpose of screening, there has to be a clear 


\section{Location 1 (callous skin)}

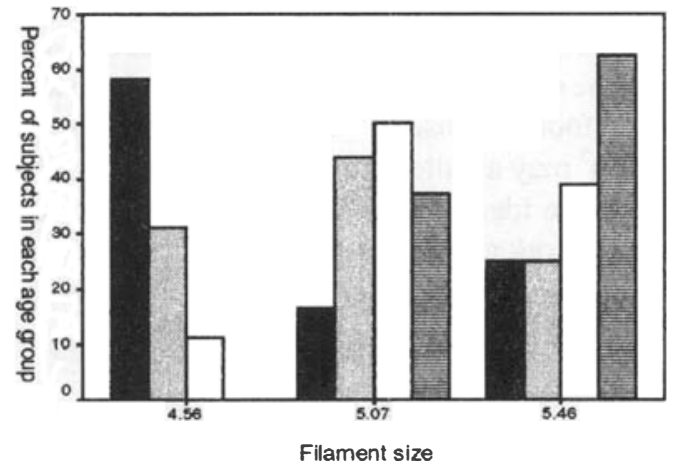

Location 9 (soft skin)

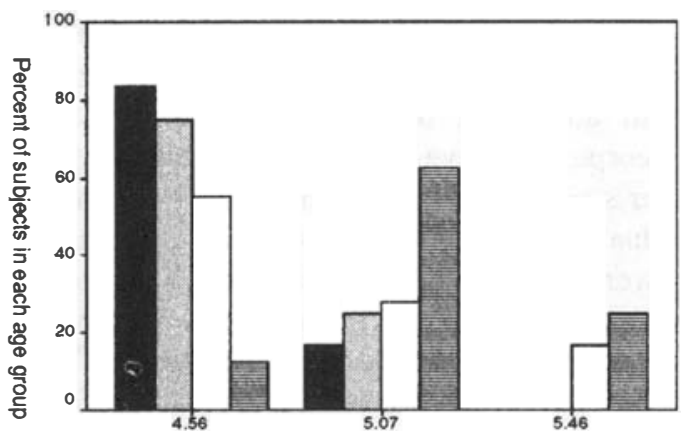

Filament size

Location 12 (heel)

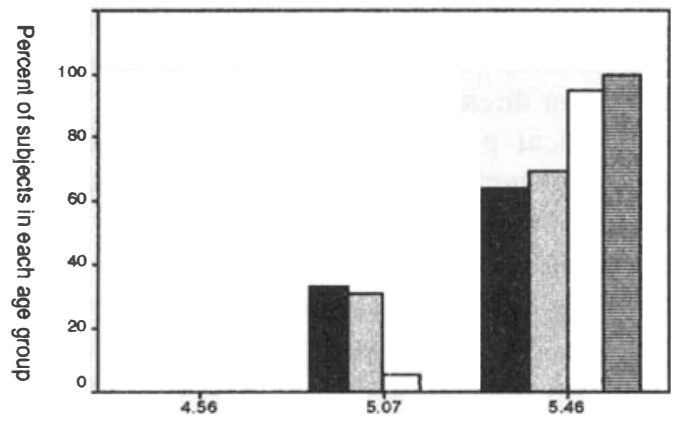

Filament size

\section{Key to age groups: $\square$ 30s $\square$ 40s $\square$ s0s}

Figure 3. Graph showing the relationship between age and sensibility threshold to light touch at location 1 (callus skin), location 9 (soft skin) and location 12 (heel). 
understanding of what is normal. A number of studies in developing countries have investigated normal sensation in the foot either as their primary aim, ${ }^{6,15}$ or as a control group when testing sensation in leprosy patients. ${ }^{9,16,17}$ Sensation might vary on the plantar aspect of the foot depending on a number of environmental factors, along with the number of years and individual lives to be exposed to these factors. It has been shown that environmental factors such as the type of footwear used, ${ }^{17}$ the degree of hydration of the skin and the physical nature of occupation ${ }^{5}$ may all alter light touch sensation. Genetic factors may also be important, as some studies have identified variation between men and women in older age groups, ${ }^{2,18,19}$ although not all work confirms this. ${ }^{20,21}$ Only a few studies have addressed the issue of the possible deterioration in light touch sensation in the foot with advancing age in a developing country. ${ }^{5,6}$ While the deterioration with age has been noted, it has not been quantified or placed in context.

Sensory acuity in the skin of the limbs to light touch, pain and vibration is known to deteriorate with age. ${ }^{4,18,20}$ Almost all studies have tested healthy individuals from the developed world, and the majority of work has investigated the hands, although a small number of studies have involved the big toe. The deterioration in sensation is more pronounced in the digits than proximally on the limb. ${ }^{22} \mathrm{~A}$ combination of alteration in the mechanical properties of the skin and neural degeneration is thought to be responsible. Histological studies have found the distribution and morphology of touch-mediating receptors to change with advancing age. Meissner's corpuscles, Merkel cell neurite complexes and Pacinian corpuscles have all been implicated in this process. The reduction in the number of Meissner's corpuscles in the skin with ageing has been shown to be quite marked, so that an individual aged in his seventies will have lost around three-quarters of the receptors he had in his twenties. ${ }^{21,23,24}$ Conduction along peripheral nerves and within the spinal cord is also slower in older persons. ${ }^{25}$ In the central nervous system, the brain weighs less with old age, the cortex is thinned and the ventricles dilated. ${ }^{26}$ All these changes help to explain how sensory thresholds in the skin of the hands and feet become elevated with advancing age.

The findings of this study show that there is a significant gradual loss of light touch sensation in the foot with advancing age in the poor rural south Asian population of Salur. This occurred at all sites tested on the foot, whether soft or callous skin. All previous studies of normal sensation in the developing world have been limited to callus skin and the potential advantages of testing soft areas have not been investigated. The closest equivalent has been the comparison between sensation in callus skin in those with shoes and those barefoot. ${ }^{17}$ The finding that light touch sensation threshold increases with age on both soft and callous skin shows that this is a neurological phenomenon and not merely due to the build up of keratinized skin due to environmental factors. In our study, those aged in their thirties were usually able to detect the 4.56 filament on the soft skin of the toes and instep, while those in their sixties were typically unable to, usually detecting only the 5.07 filament. Findings for sensory threshold over callus areas are higher than the other developing world studies who tested a healthy group. ${ }^{9,16,17}$ In our study, the lightest filament usually perceived on callus areas of the forefoot by those in their thirties and forties was the 5.07 filament, but by the fifties and sixties it was the 5.46. In all four age groups the lightest filament usually detected at the heel was the 5.46. No site anywhere on the foot in any age group was unable to detect the 5.46 filament. Results in previous work have been $4.31-5.07$ filaments $(2-10 \mathrm{~g})$ on the forefoot and 4.56-5.07 (4-10 g) on the heel. ${ }^{6,9,16,17}$ This is certainly related at least in part to their lower age range, with their mean ages similar to the very youngest in our study. 
Furthermore, our sample contained a higher proportion of heavy manual workers than other studies. The variable environmental factors affecting the degree of callosity on the areas of the foot experiencing friction will mean that the differences between sensation in different populations will be most in callus skin and least in soft skin. Any screening tool is most useful if applicable to as many populations as possible. Therefore testing soft skin should be much more uniform between groups.

The finding that the 5.46 filament is the lightest felt by the majority at the heel in all adult age groups and in the forefoot in men aged in their fifties and sixties is of great importance. Past work to determine the threshold of protective sensation necessary to prevent neuropathic plantar ulceration has advised that the 5.07 filament be used. ${ }^{9,27}$ It has been shown that skin able to detect this filament is highly unlikely to develop ulceration. However, work in Ethiopia found that many healthy individuals were failing this test, especially at the heel. ${ }^{15}$ The study presented here has confirmed the finding in patients from a different continent, showing that it is not a local phenomenon. It is interesting that sensation at the heel is poorer than other parts of the foot still covered by callous skin. This may be related to possible variation in mechanical properties of the skin at different sites of the foot, or possibly to changes in the density of sensory receptors. In the hand it has been shown that while Pacinian corpuscles and Ruffini end organs are evenly distributed over the whole glabrous skin area, Meissner's corpuscles and Merkel cell neurite complexes are much less dense on the palm than the fingers. ${ }^{28}$ While the receptors have not been studied in this detail in the foot, it is quite possible that a similar distribution would be found there too. If so, many normal individuals are failing the screening tests, especially those of older age groups; it is therefore possible that in some circumstances, a filament of higher index would be a more appropriate screening tool. In the rural population studied here, who either wore sandals or went barefoot and with a large proportion involved in heavy work, the 5.46 filament would be a suitable choice.

It is now clear that the age of an individual has a considerable effect on sensibility threshold in the foot. Increasing threshold is found with increasing age throughout adult life and this is not just a phenomenon in the elderly. This study illustrates the degree to which these changes effect light touch sensibility in a rural Indian community when tested with Semmes-Weinstein nylon monofilaments. The deterioration in sensation with age must be born in mind when testing the plantar aspect of the foot for nerve damage and therefore has great implications for the choice of monofilament by screening programmes.

\section{Acknowledgements}

Thanks are due to The Leprosy Mission, LEPRA and the St Francis Leprosy Guild for contributing towards the expenses of this research. We are also grateful to Dr Rajan Babu, Ms Catherine Benbow (OT) and to Mr E. J. Devasahayam (LCS) for valuable assistance in formulating and undertaking the study. Statistical analysis was performed by the Medical Statistics Department at University College, London.

\section{References}

1 Price EW. Studies in plantar ulcer in leprosy. V. The complications of plantar ulcer. Lepr Rev, 1960; 31: 97-103.

2 Dyck PJ, Schultz PW, Brien PC. Quantitation of touch-pressure sensation. Arch Neurol, 1972; 26: 465-473. 
3 Horch K, Hardy M, Jiminez S, Jabeley M. An automated tactile tester for evaluation of cutaneous sensibility. J Hand Surg, 1992; 17A: 829-837.

4 Thornbury JM, Mistretta CM. Tactile sensitivity as a function of age. J Gerontol, 1981; 36: 34-39.

5 Birke J, Brandsma W, Schreuders T, Piefer A. Nylon filament measurements in leprosy patients and normal subjects in Thailand. Int J Lepr, 1993; 61: 146A-147A.

${ }^{6}$ Kets CM, Van Leerdam ME, Van Brakel WH, Deville W, Bertelsmann FW. Reference values for touch sensibility thresholds in healthy volunteers. Lepr Rev, 1996; 67: 28-38.

7 Van Brakel WH, Shute J, Dixon JA, Arzet H. Evaluation of sensibility in leprosy - comparison of various clinical methods. Lepr Rev, 1994; 65: 106-121.

8 Van Brakel WH, Khawas IB, Gurung KS, Kets CM, van Leerdam ME, Drever W. Intra- and inter-tester reliability of sensibility testing in leprosy. Int J Lepr, 1996; 64: 287-298.

9 Hammond CJ, Klenerman P. Protective sensation in the foot in leprosy. Lepr Rev, 1988; 59: 347-354.

10 Levin S, Pearshall G, Ruderman R. Von Freyá'ás method of measuring pressure sensibility in the hand: an engineering analysis of the Weinstein-Semmes pressure aesthesiometer. J Hand Surg, 1978; 3: 211-216.

11 Bell-Krotoski J, Tomancik E. The repeatability of testing with Semmes-Weinstein monofilaments. J Hand Surg, 1987; 12A: 155-161.

12 McAuley DM, Ewing PA, Devasundaram JK. Effect of hand soaking on sensory testing. Int JLepr, 1993; 61: 16-19.

13 Bell-Krotoski J, Coor, V. Semmes-Weinstein monofilament detection thresholds: a comparative study. Int J Lepr, 1993; 61: 146.

14 WHO Expert Committee on Leprosy, Fourth Report. Classification of disabilities resulting from leprosy, for use in control projects. WHO Technical Report Series No.459. WHO, Geneva, 1970: 26-31.

15 Currie H, Byass P. Footsole sensation in normal subjects in Ethiopia. Int J Lepr, 1993; 61: 158.

16 Malaviya GN, Hussain S, Girdhar A, Girdhar BK. Sensory functions in limbs of normal persons and leprosy patients with peripheral trunk damage. Ind J Lepr, 1994; 66: 157-164.

17 Stratford CJ, Owen BM. The effect of footwear on sensory testing in leprosy. Lepr Rev, 1994; 65: 58-65.

18 Procacci P, Bozza G, Buzelli G, Della Corte M. The cutaneous pricking threshold in old age. Geront Clin, 1970; 12: 213-218.

19 Gescheider GA, Bolanowski SJ, Hall KL, Hoffman KE, Verillo, RT. The effects of aging on informationprocessing channels in the sense of touch: I. Absolute sensitivity. Somatosens Mot Res, 1994; 11: 345-357.

20 De Michele G, Filla A, Coppola N, Bisogno A, Trombetta L, Santorelli F, Campanella G. Influence of age, gender, height and education on vibration sense. A study by tuning fork in 192 normal subjects. J Neurol Sci, $1991 ; 105$ : $155-158$.

${ }^{21}$ Bruce MF. The relation of tactile thresholds to histology in the fingers of elderly people. J Neurol Neurosurg Psychiatry, 1980; 43: 730-734.

22 Stevens JC. Aging and spatial acuity of touch. J Gerontol, 1992; 47: 35-40.

23 Bolton CF, Winkelmann RK, Dyck PJ. A quantative study of Meissner's corpuscles in man. Neurology, 1966; 16: $1-9$.

${ }^{24}$ Schimrigk K, Ruttinger H. The touch corpuscles of the plantar aspect of the big toe. Histological and histometric investigations with respect to age. Eur Neurol, 1980; 19: 49-60.

25 Dorfman LJ, Bosley TB. Age-related changes in peripheral and central nerve conduction in man. Neurology, 1979; 29: 38-44.

26 Smith BH, Sethi PK. Aging and the nervous system. Geriatrics, 1975; May:109-115.

27 Birke JA, Sims DS. Plantar sensory threshold in the ulcerative foot. Lepr Rev, 1986; 57: 261-267.

28 Johansson RS, Vallbo AB. Tactile sensibility in the human hand; relative and absolute densities of four types of mechanoreceptive units in glabrous skin. J Physiol, 1979; 286: 283-300. 